\title{
FINGER AND PALMAR DERMATOGLYPHICS IN MUZEINA BEDOUINS FROM SOUTH SINAI: A QUALITATIVE TRAITS
}

\author{
B. Karmakar ${ }^{1}$ and E. Kobyliansky ${ }^{2}$ \\ ${ }^{1}$ Biological Anthropology Unit, Indian Statistical Institute, India \\ ${ }^{2}$ Human Population Biology Unit, \\ Department of Anatomy and Anthropology, Sackler Faculty of Medicine, \\ Tel Aviv University, Israel
}

\begin{abstract}
Qualitative finger and palmar dermatoglyphics traits of 218 individuals (170 males and 48 females), belonging to the Muzeina Bedouins- the nomadic tribe, a small isolate with a high degree of consanguinity from the South Sinai Peninsula were studied. The highest frequencies of pattern whorl (W) on the $4^{\text {th }}$ finger followed by an ulnar loop (UL) on the $3^{\text {rd }}$ finger for both hands in both sexes were observed. Similarly, the highest occurrence of pattern combinations W-W (67.7\%) was followed by the UL-UL (65.2\%) in both sexes. Finger and palmar patterns show homogeneity in nature except the $3^{\text {rd }}$ finger and the $4^{\text {th }}$ palmar area, which have a significant sex difference. The present results are not exactly similar with our previous studies on other populations Chuvashian (Karmakar et al 2007), Indians (Karmakar et al 2002), Turkmenians (Karmakar et al 2010), perhaps due to a major ethnic difference and a high inbreeding level.
\end{abstract}

Key words: Dermatoglyphics, pattern types, Bedouins. 


\section{INTRODUCTION}

The digital pattern types (polygenic nature) are frequently used to characterize human populations. In anthropological research (Cummins \& Midlo 1961, Igbigbi \& Msamati 1999, 2005, Nagy \& Pap 2005, Gasiorowski 2005), because of the prenatal origin of the dermatoglyphic patterns (Babler 1978) that remain unchanged during postnatal life. Qualitative palmar dermatoglyphic traits are considered to be largely under genetic control (Pons 1954, Glanville 1965, Karev 1991). The inter-population variability of palmar dermatoglyphics has also been ascertained (Pons 1952, Plato et al 1975, Plato \& Wertelecki 1972, Malhotra 1979, Vrydagh-Laoureux 1979, Fox et al 1987, Francis 1991, Gualdi-Russo et al 1994). Recently, qualitative traits on palmar dermatoglyphics alone have been utilized to perform the cluster analysis (Kamali et al 1992), the correspondence analysis (Martin 1991, Arreta et al 1992), or the correlation analysis to establish inter-population relationships (Sanna \& Floris 1995, Sanna et al 1998). Another wellknown important aspect is that dermatoglyphic sexual dimorphism differs in diverse populations. Cummins \& Midlo (1961) pointed out that "the usual sexual distinction may be leveled or even inverted in some populations". Females almost universally differ from males as revealed from several studies on dermatoglyphic characters in various racial samples. Compared to males, females exhibit narrower ridges, lower frequencies of whorls and radial loops, and higher frequencies of arches and ulnar loops on the fingertips (Cummins \& Midlo 1961, Schauman \& Alter 1976). Regarding palmar configurational areas, generally females have patterns more frequently on the hypothenar and the inter-digital areas compared to males (Cummins \& Midlo 1961).

The qualitative dermatoglyphic traits study is very important in Muzeina Bedouins, a highly inbreeding group. The main objective of the present study is therefore to provide information of qualitative finger and palmar patterns in Muzeina Bedouins and to compare the present result with our previous studies on Indian populations (Karmakar et al 2002a, b), the Chuvashian population of Russia (Karmakar et al 2007, 2008) and Turkmenian populations (Karmakar and Kobyliansky 2010). 


\section{MATERIALS AND METHODS}

\section{The sample and analyses of prints}

The Muzeina tribe inhabited for centuries in the Sinai desert, which was especially occupied by the Bedouins and they originated mainly from the Saudi Arabian Peninsula (Kobyliansky and Hershkovitz 1997). The Muzeina tribe is characterized by strong biological isolation, they rarely intermix and show preference for the first-cousin marriages and the inbreeding coefficient is 0.09 . The sample contains the data of 218 individuals (170 men and 48 women).

Finger and palmar prints were collected using the ink and roller method of Cummins \& Midlo (1961). Similarly, the dermatoglyphic qualitative characteristics were analyzed according to the criteria and methods of Cummins \& Midlo (1961). Dermatoglyphic traits include four types of finger patterns (UL, RL, A, W) and the palmar pattern was present and absent in 5 palmar areas namely: Hypothenar, Thenar/I, II, III, IV interdigital areas. The analyzed variables are digital pattern types which were classified into three major categories named 'Whorls', 'Loops' and 'Arches' according to Galton (1892). All the types of true whorls like concentric, single spiral, double spiral, accidental, etc. and also all the types of composite whorls like twin loops, central pocket loops, lateral pocket loops, crested and knot-crested loops are grouped under the broad category of 'whorls'. On the other hand radial and ulnar loops are categorized into 'Loops'; both simple and tented arches are grouped into the category 'Arches'. Thus, these three groups of finger patterns according to Galton (1892) are represented in an overall picture of the pattern distribution in fingers. However, in the present report, loops were classified into ulnar loops, radial loops separately, based on Cummins and Midlo (1961), and thus four digital patterns were considered in the present analysis. The symmetry of pattern types on homologous fingers and the diversity of finger pattern types present on the ten fingers were analyzed. Ten possible combinations between four types of finger patterns were considered in this analysis. 


\section{RESULTS}

\section{Finger patterns}

The frequencies of digital pattern types are presented in Table 1. The most frequently observed pattern type is the whorl (W) $49.4 \%$ in males and $50.3 \%$ in females for both hands followed by an ulner loop (UL), $46.3 \%$ in males and $45.8 \%$ in females whereas the pattern arch (A) and radial loop (RL) are less frequent than the UL and W. Arches are 1.7\% in males and $1.6 \%$ in females, while radial loops $2.9 \%$ in males and $2.4 \%$ in females. Thus the order of pattern types is $\mathrm{W}>\mathrm{UL}>\mathrm{RL}>\mathrm{A}$, both in males and females within this population.

Table 1. Frequency in the percentage (\%) of finger pattern types, by sex and hand

\begin{tabular}{|l|c|c|c|c|c|c|c|c|c|c|c|c|c|}
\hline $\begin{array}{l}\text { Pat- } \\
\text { tern }\end{array}$ & \multicolumn{4}{|c|}{ Left fingers } & \multicolumn{1}{|c|}{ Left } & \multicolumn{5}{|c|}{ Right fingers } & \multirow{2}{*}{ Right } & Both \\
\hline Type & I & II & III & IV & V & hand & I & II & III & IV & V & hand & hands \\
\hline & & & & & & Males & & & & & & & \\
\hline A & 0.0 & 8.1 & 1.4 & 0.9 & 0.0 & 2.1 & 0.0 & 5.3 & 0.5 & 1.0 & 0.0 & 1.3 & 1.7 \\
\hline RL & 0.0 & 9.0 & 0.9 & 1.9 & 0.0 & 2.4 & 0.0 & 12.5 & 0.9 & 2.4 & 0.9 & 3.3 & 2.9 \\
\hline UL & 42.2 & 48.1 & 65.4 & 28.9 & 49.5 & 46.8 & 45.0 & 43.3 & 70.6 & 24.9 & 45.0 & 45.8 & 46.3 \\
\hline W & 57.8 & 34.8 & 32.2 & 68.2 & 50.5 & 48.7 & 55.0 & 38.9 & 28.0 & 71.8 & 54.0 & 49.5 & 49.1 \\
\hline & & & & & & Femles & & & & & & & \\
\hline A & 0.0 & 6.1 & 0.0 & 2.5 & 0.0 & 1.7 & 0.0 & 6.1 & 1.2 & 0.0 & 0.0 & 1.5 & 1.6 \\
\hline RL & 0.0 & 11.0 & 3.7 & 2.5 & 1.3 & 3.7 & 1.2 & 1.2 & 0.0 & 4.9 & 1.3 & 1.7 & 2.4 \\
\hline UL & 36.6 & 47.6 & 64.2 & 17.5 & 42.3 & 41.7 & 48.8 & 53.7 & 79.3 & 19.5 & 37.2 & 47.8 & 45.8 \\
\hline W & 63.4 & 35.4 & 32.1 & 77.5 & 56.4 & 52.9 & 50.0 & 39.0 & 19.5 & 75.6 & 61.5 & 49.0 & 50.3 \\
\hline
\end{tabular}

In males, for the left hand, the highest occurrence of W (48.7\%) followed by UL (46.8\%) in males and W (52.9\%) followed by UL $(41.7 \%)$ in females. Similarly, for the right hand the highest frequency of W (49.5\%) and UL (45.8\%) are found in males; while in females W $(49.0 \%)$ and UL (47.8\%) respectively. In the case of A and RL for the left and the right hand, RL is greater than A in both sexes. Separately for the left and the right hand the order of pattern types is also $\mathrm{W}>\mathrm{UL}>$ $\mathrm{RL}>\mathrm{A}$, for both in males and females are clear.

The order of pattern frequency for the individual fingers. The order of pattern types decreases from finger to finger in the following order for W: IV $(68.2 \%)>\operatorname{I~}(57.8 \%)>V$ V $(50.5 \%)>$ II $(34.8 \%)>$ III $(32.2 \%)$ in 
males; and IV (77.5\%)>I (63.4\%)> V (56.4\%)> II (35.4\%)> III (32.1\%) in females for the left hand. Similarly for the right hand in males $\mathrm{W}$ is IV $(71.8 \%)>$ I $(55.0 \%)>$ V $(50.0 \%)>$ II $(38.9 \%)>$ III $(28.0 \%)$; and in females IV $(75.0 \%)>$ V $(61.5 \%)>$ I $(50.0 \%)>$ II $(39.0 \%)>$ III $(19.5 \%)$ respectively. Pattern UL in males for the left hand the preponderance order on different fingers is: III $(65.4 \%)>\mathrm{V}(49.5 \%)>\mathrm{II}(48.1 \%)>\mathrm{IV}$ $(28.9 \%)>\mathrm{I}(42.2 \%)$; for the right hand is III $(70.6 \%)>\mathrm{V}(45.0 \%)>\mathrm{I}$ $(45.0 \%)>$ II $(43.3 \%)>$ IV $(28.9 \%)$. For females in the left hand is III $(64.2 \%)>$ II $(47.6 \%)>V(42.3 \%)>$ I $(36.6 \%)>$ IV $(17.5 \%)$; for the right hand is III $(79.3 \%)>$ II $(53.7 \%)>$ I $(48.8 \%)>$ V $(37.2 \%)>$ IV $(19.5 \%)$ respectively.

Thus the order of pattern frequency of $\mathrm{W}$ decreases from finger to finger for the left and the right hands in both males and females in the following order IV $>$ I $>$ V $>$ II $>$ III; for UL is III $>$ V $>$ II $>$ I $>$ IV with a slight difference in both hands and sexes.

Compared to $\mathrm{W}$ and UL, A, and RL are less frequent in both sexes and for the left and the right hands; but the trend of the maximum frequency of these two patterns is found in II, III, III, and IV interdigital areas both in males and females.

Pattern combinations on the digital pairs presented in Table 2. The frequency of symmetrical patterns regarding finger pairs is similar between the right and the left hands in both sexes. Among 10 possible combinations the highest occurrence of $\mathrm{W}-\mathrm{W}(67.7 \%)$ was followed by the UL-UL (65.2\%) combination for the five categories of finger combinations. Among the five pairs of fingers, the maximum frequency of $\mathrm{W}-\mathrm{W}, 67.7 \%$ for the IV-IV pair, was followed by $52.7 \%$ for the I-I pair, $46.3 \%$ for the $\mathrm{V}-\mathrm{V}$ pair in males. The decreasing order of pattern frequency among the five categories of finger combinations for $\mathrm{W}-\mathrm{W}$ is IV-IV $>$ I-I $>$ V-V $>$ II-II $>$ III-III, in males. Similarly for females with a very slight difference is IV-IV $(77.0 \%)>\mathrm{V}-\mathrm{V}(55.4 \%)>\mathrm{I}-\mathrm{I}(55.2 \%)>$ II-II $(29.5 \%)>$ III-III $(14.5 \%)$ respectively.

The maximum frequency of UL-UL, $65.2 \%$ for the III-III pair, was followed by $42.6 \%$ for the $\mathrm{V}-\mathrm{V}$ pair in males among the five pairs of fingers. However, for females the frequencies are slightly different in UL-UL combination, III-III (72.6\%)> I-I (38.8\%) > II-II $(37.7 \%)>$ V-V $(30.8 \%)>\operatorname{IV}-\mathrm{IV}(16.2 \%)$. 
Table 2. Pattern combinations (in \%) between the pairs of homologous fingers

\begin{tabular}{|l|c|c|c|c|c|c|c|c|c|c|}
\hline Pairs of & & & & \multicolumn{2}{|c|}{ Pattern combination } & & & & \\
\hline fingers & A-A & $\begin{array}{c}\text { LR- } \\
\text { LR }\end{array}$ & $\begin{array}{c}\text { UL- } \\
\text { UL }\end{array}$ & W-W & A-LR & $\begin{array}{c}\text { A- } \\
\text { LU }\end{array}$ & A-W & $\begin{array}{c}\text { LR- } \\
\text { LU }\end{array}$ & $\begin{array}{c}\text { LR- } \\
\text { W }\end{array}$ & $\begin{array}{c}\text { LU- } \\
\text { W }\end{array}$ \\
\hline & & & & & Males & & & & & \\
\hline I-I & 0.0 & 0.0 & 39.4 & 52.7 & 0.0 & 0.0 & 0.0 & 0.0 & 0.0 & 8.0 \\
\hline II-II & 2.3 & 5.3 & 35.7 & 32.2 & 0.0 & 4.1 & 1.2 & 5.8 & 0.6 & 12.9 \\
\hline III-III & 0.6 & 0.0 & 65.2 & 21.9 & 0.0 & 0.0 & 0.0 & 1.1 & 0.0 & 11.2 \\
\hline IV-IV & 0.5 & 0.5 & 19.8 & 67.7 & 0.0 & 0.5 & 0.0 & 1.0 & 0.5 & 9.4 \\
\hline V-V & 0.0 & 0.0 & 42.6 & 46.3 & 0.0 & 0.0 & 0.0 & 0.0 & 0.0 & 11.1 \\
\hline Total & 0.7 & 1.1 & 40.3 & 44.7 & 0.0 & 0.9 & 0.2 & 1.5 & 0.2 & 10.4 \\
\hline & & & & & Females & & & & & \\
\hline I-I & 0.0 & 0.0 & 38.8 & 55.2 & 0.0 & 0.0 & 0.0 & 0.0 & 0.0 & 6.0 \\
\hline II-II & 1.6 & 0.0 & 37.7 & 29.5 & 1.6 & 4.9 & 0.0 & 1.6 & 3.3 & 19.7 \\
\hline III-III & 0.0 & 0.0 & 72.6 & 14.5 & 0.0 & 1.6 & 0.0 & 0.0 & 1.6 & 9.7 \\
\hline IV-IV & 0.0 & 1.4 & 16.2 & 77.0 & 0.0 & 0.0 & 1.4 & 1.4 & 1.4 & 1.4 \\
\hline V-V & 0.0 & 0.0 & 30.8 & 55.4 & 0.0 & 0.0 & 0.0 & 0.0 & 0.0 & 13.8 \\
\hline Total & 0.3 & 0.3 & 38.3 & 47.7 & 0.3 & 1.2 & 0.3 & 0.6 & 1.2 & 9.7 \\
\hline
\end{tabular}

Table 3 presents the frequency of individuals with monomorphic hands, i.e. bearing the same pattern on all the ten fingers. The highest frequency was found (male $54.6 \%$, female $65.8 \%$ ) for the combination $\mathrm{UL}+\mathrm{W}$ out of 15 combinations. The pattern W (9.3\%), UL (4.6\%) and $\mathrm{UL}+\mathrm{RL}(3.1 \%)$ are found in males, whereas in females they were $4.1 \%$, $1.4 \%$ and $1.4 \%$ respectively. Pattern $\mathrm{W}$ shows a higher frequency (male $-9.3 \%$, female $4.1 \%$ ) compared with UL (male $-4.6 \%$, female $1.4 \%$ ). 
Table 3. Frequency of pattern type combinations on the ten fingers in males and females

\begin{tabular}{|l|c|c|c|c|}
\hline \multirow{2}{*}{ Pattern } & \multicolumn{2}{|c|}{ Males } & \multicolumn{2}{c|}{ Females } \\
\cline { 2 - 5 } & N. & $\%$ & N. & $\%$ \\
\hline A only & - & - & - & - \\
\hline RL only & - & - & - & - \\
\hline UL only & 9 & 4.6 & 1 & 1.4 \\
\hline W only & 18 & 9.3 & 3 & 4.1 \\
\hline A + RL & - & - & - & - \\
\hline A + UL & 7 & 3.6 & 1 & 1.4 \\
\hline A + W & - & - & - & - \\
\hline RL + UL & 6 & 3.1 & 1 & 1.4 \\
\hline RL + W & - & - & - & - \\
\hline UL + W & 106 & 54.6 & 48 & 65.8 \\
\hline A + RL + UL & 1 & 0.5 & - & - \\
\hline A + RL + W & - & - & - & - \\
\hline A + UL + W & 11 & 5.7 & 6 & 8.2 \\
\hline RL+UL+ W & 29 & 14.9 & 12 & 16.4 \\
\hline A + RL + UL + W & 7 & 3.6 & 1 & 1.4 \\
\hline Total & 194 & 100.0 & 73 & 100.0 \\
\hline
\end{tabular}

\section{Palmar patterns}

The occurrence of patterns represented in the terms of the pattern present and absent in five palmar configurational areas is shown in Table 4. [Please, put Table 4 here] A general trend of a rich frequency at the same pattern was present in males on both palms IV $(30.3 \%)>$ $\mathrm{Th} / \mathrm{I}(15.3 \%)>\operatorname{III}(8.0 \%)>\mathrm{II}(2.6 \%)>$ Hyp $(1.5 \%)$, whereas in females it was present on IV $(46.2 \%)>\mathrm{Th} / \mathrm{I}(16.8 \%)>\mathrm{III}(6.5 \%)>\mathrm{II}(3.2 \%)>$ Hyp $(0.0 \%)$ respectively. The poorer patterns are on the Hypothenar and the second interdigital areas in both sexes. The frequencies of the same pattern are higher in most of the areas compared with the different types of the pattern. The bilateral symmetry of the presence/absence of the pattern is more pronounced both in males and females, in the Hypothenar (male 94.5\%, female 96.8\%) and the II interdigital areas (male $95.6 \%$, female $94.7 \%$ ). The presence of the palmar pattern only on the left or the right hands varies in different palmar areas in both sexes. 
Table 4. Percent distribution of palmar patterns in males (M) and females (F)

\begin{tabular}{|l|c|c|c|c|c|c|c|c|c|c|}
\hline \multirow{2}{*}{$\begin{array}{l}\text { On both } \\
\text { palms: }\end{array}$} & \multicolumn{9}{|c|}{} & \multicolumn{6}{|c|}{ Interdigital } \\
\cline { 2 - 11 } & Hypothenar & \multicolumn{2}{|c|}{ Thenar } & \multicolumn{3}{|c|}{ II } & \multicolumn{3}{|c|}{ III } & \multicolumn{2}{|c|}{ IV } \\
\cline { 2 - 11 } & $\mathrm{M}$ & $\mathrm{F}$ & $\mathrm{M}$ & $\mathrm{F}$ & $\mathrm{M}$ & $\mathrm{F}$ & $\mathrm{M}$ & $\mathrm{F}$ & $\mathrm{M}$ & $\mathrm{F}$ \\
\hline Absent & 94.2 & 96.8 & 62.0 & 54.7 & 93.4 & 91.5 & 63.5 & 66.7 & 41.6 & 26.9 \\
\hline Present & 1.5 & 0.0 & 15.3 & 16.8 & 2.6 & 3.2 & 8.0 & 6.5 & 30.3 & 46.2 \\
\hline $\begin{array}{l}\text { Same } \\
\text { pattern }\end{array}$ & 0.4 & 0.0 & 10.6 & 13.7 & 2.2 & 3.2 & 8.0 & 5.4 & 28.1 & 40.9 \\
\hline $\begin{array}{l}\text { Different } \\
\text { pattern }\end{array}$ & 1.1 & 0.0 & 4.7 & 3.2 & 0.4 & 0.0 & 0.0 & 1.1 & 2.2 & 5.4 \\
\hline $\begin{array}{l}\text { Bilateral } \\
\text { symmetry }\end{array}$ & 94.5 & 96.8 & 72.6 & 68.4 & 95.6 & 94.7 & 71.5 & 72.0 & 69.7 & 67.7 \\
\hline $\begin{array}{l}\text { Pattern } \\
\text { only on: }\end{array}$ & & & & & & & & & & \\
\hline Left palm & 4.0 & 3.2 & 9.5 & 9.5 & 1.5 & 2.1 & 4.0 & 2.2 & 21.9 & 20.4 \\
\hline Right palm & 0.4 & 0.0 & 13.1 & 18.9 & 2.6 & 3.2 & 24.5 & 24.7 & 6.2 & 6.5 \\
\hline
\end{tabular}

\section{Sex comparisons}

Finger pattern frequencies between sexes show little variations, a significant sex difference is found only for the $3^{\text {rd }}$ finger $(0.023)$ out of all digits and thus shows homogeneity in nature (Table 5). Out of five digital pairs of pattern combinations, only II-II pair is significantly (0.041) different between sexes. Finger patterns and palmar patterns exhibit almost similar variation, out of five palmar areas, only IV (0.025) area is significantly different. The remaining Hypothenar and Thenar/I areas are homogeneously distributed in both sexes. 
Table 5. Sex comparisons by $\chi^{2}$ test of finger and palmar patterns

\begin{tabular}{|l|ccc|}
\hline Variables & d.f. & $\chi^{2}$ & $\mathrm{p}$ \\
\hline Finger pattern & & & \\
L I & 1 & 0.76 & 0.383 \\
II & 3 & 0.36 & 0.948 \\
III & 3 & 2.94 & 0.401 \\
IV & 3 & 3.97 & 0.265 \\
V & 2 & 3.74 & 0.154 \\
All & 3 & 0.95 & 0.801 \\
R I & 2 & 2.95 & 0.229 \\
II & 3 & 9.51 & $\mathbf{0 . 0 2 3}$ \\
III & 3 & 3.42 & 0.331 \\
IV & 3 & 3.80 & 0.284 \\
V & 2 & 0.57 & 0.752 \\
All & 3 & 0.34 & 0.952 \\
10 Fingers & 3 & 0.13 & 0.968 \\
\hline Pattern combination & & & \\
I-I & 2 & 1.3 & 0.522 \\
II-II & 9 & 17.5 & $\mathbf{0 . 0 4 1 *}$ \\
III-III & 6 & 10.3 & 0.113 \\
IV-IV & 8 & 10.1 & 0.258 \\
V-V & 2 & 3.4 & 0.830 \\
Pattern comb. 10 fingers & 8 & 9.20 & 0.326 \\
\hline Palmar patterns & & & \\
Hyp & 3 & 3.32 & 0.348 \\
Th-I & 3 & 1.28 & 0.729 \\
II & 3 & 1.71 & 0.635 \\
III & 3 & 0.69 & 0.876 \\
IV & 3 & 9.31 & $\mathbf{0 . 0 2 5 *}$ \\
\hline
\end{tabular}

* Marked differences are significant when $\mathrm{p}<0.05$.

\section{DISCUSSION}

From the above presentation, it appears that there is a homogeneous distribution of pattern types regarding the fingers and the palmar configurational areas between sexes and between the right and the left sides with a very little variation. Therefore, a trend of similarity is observed in these areas. The Bedouin population is characterized by 
having high frequencies of whorls, compared to loops and low frequencies of arches and radial loops those are almost uniformly distributed on all the fingers and in both sexes $(\mathrm{W}>\mathrm{UL}>\mathrm{RL}>\mathrm{A})$. The decreasing order from finger to finger is for W: IV $>I>V>I I>I I I$; for UL: III $>$ V $>$ II $>I>I V$; and for A: II $>$ III $>$ IV respectively. These findings are not corroborated by earlier studies in different non-tribal populations: Micle and Kobyliansky (1987) in Yemenite Jews; Micle \& Kobyliansky (1988) among North African Jews; Arrieta et al. (1991) among Basque from Salazar valley; Crawford and Duggirala (1992) among Eskimo and Amerindians; Dittmar (1994) among Chilean Aymara Indians; Sivakova et al. (1995) among North Slovakia Isolates; Karmakar et al. (2002), and Sengupta and Karmakar (2003) among Indian populations; Karmakar et al. (2007) among the Chuvashian population of Russia; Karmakar et al. (2010) among Turkmenian populations. The above studies observed the decreasing order of digital pattern frequency is $\mathrm{UL}>\mathrm{W}>\mathrm{A}>\mathrm{RL}$ and decreases from finger to finger mostly in the following order V $>$ III $>$ I $>$ IV $>$ II. Holt (1968) stated that certain patterns tend to occur more frequently on some digits than on others, which seem to be constant for any population. Roberts (1982) concluded that qualitative dermatoglyphic traits are a complex outcome of the developmental process in which individual digits of the same genetic fields occur but at different locations. The dermatoglyphics of the Muzeina Bedouin tribe, biologically a small isolated consanguineous population, is perhaps expected to have some differences in the digital pattern expression than in other non-inbreeding/non-tribal populations. Our results are similar with the earlier well-known hypothesis (Cummins and Midlo 1961) that the highest frequency of $\mathrm{W}$ is a common characteristic feature of tribal populations, which indicates a simpler genetic basis due to the consanguinity/isolation of the Muzeina Bedouin tribe. Similarly, for pattern combinations, the highest occurrence of W-W (67.7\%) was followed by the UL-UL $(65.2 \%)$ combination for five categories of finger combinations.

The present finding ( $\mathrm{W}>\mathrm{UL}>\mathrm{RL}>\mathrm{A}$ ) is in full conformity to the general trends observed earlier on tribal populations (Cummins and Midlo 1961, Malhotra 1974, Kumar and Ramchandraiah 1991, Deka et al 1991, Sengupta and Karmakar 2004). The dermatoglyphic features are in close conformity to the other nomadic/tribal populations perhaps due to isolated tribes are small in numerical strength and thus the scope 
for the founder effect and the random genetic drift are also greater among them. Malhotra et al. (1980) explained that such frequency of patterns among the Nandiwallas are due to the genetic drift and the similar evolutionary forces acting in the same direction among the nomads were responsible for the observed similarity of dermatoglyphic features among them.

A general trend of a rich frequency of palmar pattern present in IV interdigital area on both palms in both sexes is similar with the earlier studies in different populations (Karmakar et al 2002, 2007, 2010). The finger and palmar patterns show homogeneity in nature except the $3^{\text {rd }}$ finger and the $4^{\text {th }}$ palmar area, which have a significant sex difference. The present results are not exactly similar with our previous studies on other populations - Chuvashian (Karmakar et al 2007), Indians (Karmakar et al 2002), Turkmenians (Karmakar et al 2010), perhaps due to a major ethnic difference and the inbreeding level in the Muzeina tribe.

\section{REFERENCES}

1. Arrieta MI, Martinez B, Criado B, Lobato N, Lostao CM (1992) Genetic and dermatoglyphic distances among Basque valleys. Hum Biol 64, pp 705-716.

2. Arrieta MI, Salazar I, Criado B, Martinez B, Lostao, CM (1991) Twin study of digital dermatoglyphic traits: investigation of heritability. $\mathrm{Am} \mathrm{J}$ Hum Biol 3, pp 11-15.

3. Babler WJ (1978) Prenatal selection and dermatoglyphic patterns. Am J Phys Anthrop 48, pp 21-28.

4. Crawford MH, Duggirala R (1992) Digital dermatoglyphic patterns of Eskimo and American populations: Relationships between geographic, dermatoglyphic, genetic and linguistic distances. Hum Biol 64, pp 683704.

5. Cummins H, Midlo C (1961) Finger prints, palms and soles. Dover Publ. New York.

6. Dittmar M (1994) Qualitative and quantitative analysis of digital and palmar dermatoglyphics in Chilean Aymara Indians. Anthropologia Biologica 2, pp 39-58.

7. Deka U, Ghosh Maulik SK, Das PK (1991) Reexamination of Mundari ethnic affinities through dermatoglyphic data. In: Dermatoglyphics 
Today, Reddy BM, Roy SB, Sarkar BN (eds.), IBRAD, ASI, \& ISI publ., 311-321.

8. Fox KM, Garruto RM, Gajdusek DC (1987) A review of the dermatoglyphics of Micronesia. Coll Antropol 11, pp 355-372.

9. Francis J (1991) A comparative study of palmar C- line polymorphism among the two communities of Kerala. In: (BM. Reddy, SB Roy, BN Sarkar Ed.). Dermatoglyphics Today, 367-372. IBRAD, Calcutta.

10. Galton F (1892) Finger Prints. Macmillan and Co., London.

11. Gasiorowski A (2005) Regional differentiation of palm dermatoglyphes in rural population in Poland. Ann Agric Environ Med 12, pp 277-280.

12. Glanville EV (1965) Heredity and line A of palmar dermatoglyphics. Am J Hum Genet 17, pp 420-424.

13. Gualdi-Russo E, Facchini F, Brasili-Gualandi P, Gruppioni G, Pettener D (1994) Digital and palmar dermatoglyphics and the population structure of the upper Bologna Apennine. Ann Hum Biol 21, pp 519-532.

14. Holt SB (1968) The genetics of dermal ridges. CC. Thomas, Springfield (III).

15. Igbigbi PS, Msamati BC (1999): Palmar and digital dermatoglyphic patterns in Malawian subjects. East Afr Med J 76, pp 668-671.

16. Igbigbi PS, Msamati BC (2005) Palmar and digital dermatoglyphic traits of Kenyan and Tanzanian subjects. West Afr J Med 24, pp 26-30.

17. Kamali MS, Mavalwala J (1992) Diversity of palmar patterns in Iranian populations. Coll Antropol 16, pp 383-393.

18. Karev GB (1991) Hypothener radial arch in man: Observations on its distribution, morphology, symmetry and inheritance. Am J Phy Anthrop 84, pp 479-487.

19. Karmakar B, Yakovenko K, Kobyliansky E (2002a) Dermatoglyphic sexual dimorphism: Finger and palmar qualitative characteristics in five endogamous populations of West Bengal, India. Anthrop Anz 60, pp 273-292.

20. Karmakar B, Yakovenko K, Kobyliansky E (2007) Qualitative finger and palmar dermatoglyphics: Sexual dimorphism in the Chuvashian population of Russia. Anthrop. Anz. Vol 65 (4), pp 383-390.

21. Karmakar B, Kobyliansky E (2010) Qualitative and quantitative finger and palmar dermatoglyphics: Sexual dimorphism in the Turkmenian population. In: Research in Physical Anthropology: Essays in honor of Professor L.S. Penrose, Editor S. Datta Banik, unas Letras industria editorial Publ, Merida, Yucatan, Mexico, Chapter 6, pp 115-145.

22. Kobyliansky E. and Hershkovitz I.: Biology of Desert Populations South Sinai Bedouins: Growth and Development of Children in Human 
Isolates. Etudes et Rech. Archeologiques de l'Universite de Liege, Belgium. 1997, p 283.

23. Kumar VSD, Ramachandrah T (1991) Finger and palmar dermatoglyphic study among the Narikorava. In: Dermatoglyphics Today, Reddy BM, Roy SB, Sarkar BN (eds.), IBRAD, ASI, \& ISI publ., 343355.

24. Malhotra KC (1974) Socio-biological investigations among the Nandiwallas of Maharashtra. Bull Urgent Anthrop Ethnol Sci 16, pp 63-102.

25. Malhotra KC (1979) Qualitative finger dermatoglyphic variation among 21 endogamous Dhangar castes of Maharashtra. Birth Defects: Original article series. 15, pp 335-345.

26. Malhotra KC, Vijaya Kumar M, Khomne SB (1980) Palmar dermatoglyphics in three nomadic Mendelian isolates. In: IJS Bansal (ed.) Human Biology-Recent Advances (Vol. 21). New Delhi : Today \& Tomorrow's printer \& publishers, pp 285-307.

27. Martin J (1991) Palmar C-line polymorphism in Spain. In: (BM. Reddy, SB Roy and BN Sarkar eds.). Dermatoglyphics today, pp 245255. IBRAD, Calcutta.

28. Micle S, Kobyliansky E (1987) Dermatoglyphic sexual dimorphism in Yemenite Jews. Bull. et Mem de la soc d'Anthrop. De Paris $t$ 4, ser. XIV, no. 2, pp 95-114.

29. Nagy AS, Pap M (2005) Pattern influence on the fingers. Homo 56, pp 51-67.

30. Plato CC, Wertelecki W (1972) A method for sub classifying the interdigital patterns: A comparative study of the palmar configurations. Am J Phys Anthrop 37, pp 97-110.

31. Plato CC, Cereghino JJ, Steinberg FS (1975) The dermatoglyphics of American Caucasian. Am J Phys Anthrop 42, pp195-210.

32. Pons J (1952) Impresiones dermopapilares en universitarios Barcelonenses. Trabajos Inst B. de Sahagun de Antrop. Y. Etnol. 13, pp 87131 .

33. Pons J (1954) Herencia de las lines principales de la palma. Contribution a la genetica de los caracteres dermopapilares. Trabajos Inst B de Sahagun de AntropY Etnol 14, pp 35-50.

34. Roberts. D.F. (1982) Population variation in dermatoglyphics: Field theory. In Bartsocas CG (ed): Progress in dermatoglyphic research. Alan R Liss, New York, 79-91. 
35. Sanna E, Floris G (1995) Polymorphism of palmar main line terminations as an indicator of relationships among Sardinian linguistic groups of males. Hum Biol 67, pp 265-282.

36. Sanna E, Usai E, Floris G. (1998) Palmar pattern frequencies as indicators of relationships among Sardinian linguistic groups of males. Int J Anthropol 13, pp 65-80.

37. Schauman B, Alter M (1976) Dermatoglyphics in Medical disorders. Springer Verlag, New York.

38. Sengupta M, Karmakar B (2003) Intergenerational trend of some Dermatoglyphic traits in Vaidyas of West Bengal, India. Coll Antropol 27(2), pp 515-521.

39. Sengupta M, Karmakar B (2004) Interethnic comparisons of three endogamous groups of West Bengal with respect to two sets of variables. Int J Anthropol Vol 19 (3), pp 193-212.

40. Sivakova D, Pospisil M, Hroziencikova O (1995) Genetic studies in a North-Slovakia isolate: Chmelnica 3. Dermatoglyphic traits. $Z$ Morph Anthrop 81, pp 67-77.

41. Vrydagh-Laoureux S (1979) Digital and palmar dermatoglyphics in a sample of Maroccans. Hum Biol 51, pp 537-549.

\section{Address for correspondence:}

Dr. Bibha Karmakar,

Biological Anthropology Unit, Indian Statistical Institute, 203 B.T.Road, Kolkata 700 108, India.

E-mail: bibha@isical.ac.in

Prof Eugene Kobyliansky, Human Population Biology Unit, Department of Anatomy and Anthropology, Sackler Faculty of Medicine, Tel Aviv University, Ramat Aviv, Tel Aviv 69978, Israel E-mail: anatom14@post.tau.ac.il 